\title{
Developmental Delay and Its Predictors Among Under-Five Uncomplicated Severe Acute Malnourished Children: a Cross-Sectional Study in Rural Areas of Pakistan
}

Javeria Saleem

University of the Punjab

Rubeena Zakar

University of the Punjab

Gul Mehar Javaid Bukhari

Federal Mental and Dental College

Aneela Fatima

Pakistan Council of Scientific and Industrial Research

Florian Fischer ( $\square$ florian.fischer1@charite.de)

Charite Universitatsmedizin Berlin https://orcid.org/0000-0002-4388-1245

\section{Research}

Keywords: nutrition, malnutrition, paediatrics, children, determinant

Posted Date: August 12th, 2020

DOI: https://doi.org/10.21203/rs.3.rs-57484/v1

License: (c) (i) This work is licensed under a Creative Commons Attribution 4.0 International License.

Read Full License 


\section{Abstract}

Background: In developing countries, malnutrition in children and developmental delays are two major challenges for public health. To achieve the vision of the Sustainable Development Goals in the broader perspective of child health, an early identification of developmental delays and timely intervention is crucial. The aim of this study is to assess the prevalence of suspected developmental delay and their predictors in under-five uncomplicated severe acute malnourished children in rural areas of Pakistan.

Methods: A multicentre cross-sectional study has been conducted among 185 uncomplicated severe acute malnourished children. We screened 6-59 months aged children for their nutritional status and clinical complications. Children fulfilling the inclusion criteria underwent the Denver Development Screening Tool II (DDSTII). The global developmental profile of children was calculated according to established protocols of DDSTII based on four important domains of development: personal and social behaviour, language, gross motor adaptive and fine motor adaptive skills. A pretested structured questionnaire on socio-demographic and nutritional factors was used for assessing predictors of developmental delay, which were analysed in a multivariate logistic regression model.

Results: Out of 177 severe acute malnourished children, 69 (38.9\%) had normal global development and 108 (61.1\%) had delayed global development. Significant associations with global development delay were found for lower aged children (6-24 months vs. 25-59 month; AOR=4.53, 95\% Cl: 1.56-13.10, $p<0.01$ ), not exclusively breastfeed children ( $A O R=3.07,95 \% \mathrm{Cl}: 1.24-7.56, p=0.01$ ), and a history of contact with tuberculosis smear positive adult (AOR=2.67, 95\% Cl: $1.30-5.49, p<0.01)$.

Conclusion: With about two thirds of study participants showing delayed or unstable global development, there is a high prevalence of suspected developmental delay among under-five uncomplicated severe acute malnourished children in rural areas Pakistan. Particularly children in their first two years of life with insufficient breastfeeding are at high risk. This emphasizes the need for providing adequate infrastructure and information to parents in remote areas.

\section{Background}

Developmental delay indicates extensive deficits and lack of developmental skills that would be appropriate for children of their respective age. It may exhibit in different domains, including motor adaptive skills, language as well as personal and social behaviour [ ]. Grantham et al. [ suggested that globally approximately more than $\mathbf{2 0 0}$ million children under-five are unable to attain their developmental potential due to poverty, malnutrition, inappropriate child care, and child abuse. Most of them belong to South Asia and sub-Saharan Africa.

Severe acute malnutrition (SAM), also known as severe wasting, represents the most critical form of undernutrition. It is further classified as complicated and uncomplicated SAM based on the presence of medical complications []. Children with medically complicated SAM will mostly be treated as inpatients in a facility, but children with uncomplicated severe acute malnutrition are advised to be nursed at home 
with high calorie, micronutrient enriched food [. SAM is responsible for a large part of global disease burden among children and has a high lethality (10-30\%). Those children who survive have compromised physical and cognitive development, which could deteriorate economic productivity in adulthood [, ].

Early childhood, known as the first 5 years of life, is the fastest and most sensitive period of child growth and brain development. This period is easily influenced by poverty, biological and psychosocial risk factors $\left[{ }^{1},\right]$. The link between nutritional status of children and developmental profile in this period cannot be overstated, particularly in developing countries, as numerous studies have proven strong acquaintances among them [, , ]. Malnutrition and scarce stimulus have the potential to ruffle the progression of rapid brain development by adversely affecting the structural and functional capacity of the brain resulting in developmental deficits of children in all domains [3, ]. The unconstructive society or child external environment also has a negative impact on a child's ability to accomplish his or her full social and developmental skills $\left[{ }^{11}\right]$. Therefore, several social, biological and psychological factors might contribute to developmental delay in children [1]

To achieve the Sustainable Development Goals (SDGs) vision in the broader perspective of child health beyond survival, particularly SDG 3 and 4 need actions. It is inevitable to monitor the proportion of children under-five years who are accomplishing their developmental potential in health, education, and psychosocial well-being, disaggregated by gender, age, disability, geographical location, and other attributes [. Globally, an estimated 19 million children suffer from severe acute malnutrition. Of these, around 1.4 million children are from Pakistan [ $\left.{ }^{6}\right]$. Like other developing countries, Pakistan is struggling with the public health issue of child malnutrition, showing rates for stunting of $40.2 \%$ and for wasting of $17.7 \%$ [.

Despite the already available data on the nutritional profile of under five children in Pakistan, there is still a scarcity of data to depict how malnutrition correlates to developmental potentials of children. Moreover, the factors influencing delays in child development, the associations between these factors, as well as their direct and indirect relationship with developmental outcome in severe acute malnourished children have been seldomly examined. For that reason, the objective of this study is to assess the prevalence of developmental delay and its predictors among under-five uncomplicated severe acute malnourished children in rural regions of Pakistan.

\section{Methods}

\section{Study area, design and population}

A multicentre cross-sectional study was conducted during the period of one year at the end of 2016 at four Outpatient Therapeutic Programme (OTP) Centre's in the District Dera Ghazi Khan of Southern Punjab, Pakistan. Dera Ghazi Khan has the worst indicators of malnutrition (stunting and wasting) in 
Punjab. This socio-economically underprivileged district has the highest prevalence of illiteracy and overcrowding and is frequently affected by floods [16,[i]].

Overall 185 children, aged 6 to 59 months, were selected to participate in the study in case of their parents' written informed consent. At enrolment, these children had severe acute malnutrition (SAM) without complications according to World Health Organization (WHO) criteria (mid-upper arm circumference [MUAC] $115 \mathrm{~mm}$ and a weight-for-height [Z score]<-3), were clinically well, alert and had good appetite. Severe acute malnourished children with complications were not included in the study on baseline assessment. Complications, as defined by WHO, were hypoglycaemia, hypothermia (axillary temperature $<35^{\circ} \mathrm{C}$ ), hyperpyrexia (axillary temperature $>39^{\circ} \mathrm{C}$ ), anorexia, severe dehydration, grade three pitting oedema, severe anemia and acute lower respiratory tract infection [5].

\section{Sample size}

For sample size calculation, WHO Sample Size 2.0 and the following formula have been used:

$$
n=\frac{Z^{2} \cdot P \cdot(1-P)}{d^{2}}
$$

with a level of significance of $95 \%(Z=1.96)$, an expected proportion of wasting $(P)$ of $11 \%$ [17], and an expected error (d) of $5 \%$. This leads to a sample size of 151 , which was inflated to a total of 185 to enhance study precision, strength, and accuracy. The eligibility to participate in the study was assessed among 252 children; 67 were excluded, because they either did not meet the inclusion criteria $(n=52)$ or parents refused to participate $(n=15)$ (Figure 1$)$.

\section{Data collection and exclusion criteria}

A structured and pretested questionnaire was used for face-to-face interviews with parents to assess data on socio-demographic characteristics and nutritional consumption. Interviews with parents and child physical examination were conducted at OTP centers.

Gestational age of mothers was taken from antenatal records in case of hospital delivery or was based on maternal recall if the birth has been conducted at home. The age of children $\leq 24$ months and born before 37 weeks of gestation was adjusted by deducting the number of weeks of missed gestation from the present age.

Medical history was obtained for symptoms of acute diarrhea, high grade fever, lethargy, cough, shortness of breath, seizures, neurological deficit and anorexia. All of these symptoms were indications for a child being clinically ill. In physical examination, severe dehydration, palmar pallor (as an indication for anemia), and severe pitting edema was assessed in children [4, 5]. Children's vital signs were assessed for hypothermia/hyperpyrexia and respiratory rate. For assessment of hypoglycemia, a heel-prick was done and children with glucose concentration of $<3 \mathrm{mmol} / \mathrm{L}$ based on the Dextrostix reagent strip were deemed to be hypoglycemic. Appetite test was conducted by giving the child a small amount of ready-to- 
use therapeutic food (RUTF) to eat. The child who did not consume a minimum one third of a packet (three teaspoons, which is $30 \mathrm{~g}$ ) of RUTF after three tries were labeled as poor appetite $[4,5,6]$. Children evaluated as being clinically ill due to the aforementioned symptoms and classified as having poor appetite were not included in the study. Instead they were referred to an inpatient facility.

\section{Measurements}

\section{Anthropometric measurements}

Anthropometric assessments were conducted by trained staff that. Assessments were made twice by a study team to avoid potential bias. In case both measurements differed, further assessments were done till a precise value was obtained. The repeated value was then documented. The mid upper arm circumference was assessed to the proximate $0.1 \mathrm{~cm}$ with color-labeled MUAC tape at the midpoint among the olecranon and the acromion process.

Child weight was measured with UNISCALE, close to $10 \mathrm{~g}$ undressed or in a light dress. If children and infants were not able to stand by themselves, UNISCALE was utilized to determine only mothers' weight. Afterwards, the infant/child was handed over to the mother while she was standing on the scale and the collective infant and mother weight was assessed. The calculation of infant/child weight was made as the difference among these two readings. UNISCALE was calibrated for standard weight and adjusted to zero prior to all measurements.

The recumbent length of child who were less than or equal to $87 \mathrm{~cm}$ in height was assessed to the proximate $0.1 \mathrm{~cm}$ with the help of a length-measuring board with a fixed headrest and a mobile foot piece ("SECA GmbH \& Co. KG, Hamburg, Germany"), laid on a smooth surface. Children larger than $87 \mathrm{~cm}$ in height were assessed in the stand-up position after removing shoes and with heels together on a horizontal flat plate attached to the base of the measuring board [[ii]]. Standard protocols for child growth were applied for calculating the weight-for-height Z-score with WHO ANTHRO version 3.2.2.

\section{Developmental screening}

Study participants underwent the Denver Development Screening Tool II (DDST II) [[iii]] for assessing the development profile. This tool measures the children's proficiency, under the age of six years to do a range of different tasks and make comparisons with a standardized population of same age children. It measures the four parameters of development that is personal-social behavior development, fine motor development, language, and gross motor development. This tool was executed by a physician trained in conducting DDST II for child development assessment. The average screening time for DDST II was about 30 minutes. If the child was uncooperative and untestable at the first screening for global developmental status, a follow up rescreen visit has been conducted after two days. If the child was still untestable, the screening was repeated again after two days. The tool was translated into the native language for elimination of communication barrier. The flowchart of developmental screening is presented in Figure 1. 
Following a standardized algorithm, child's development was categorized as "normal (if child performs the items, on the left of age line completely), caution an intermediate classification (if child is unsuccessful or say no on an item on which age line falls on or between the 75th and 90th percentiles), or delay (if child isn't passing an item that $90 \%$ of children in the standardization passed at an earlier and item on which age line falls completely to the left of the age line)" [19]. These category measurements were then applied to grade global developmental status as "normal" (no category delayed and no more than one category classified as caution), "suspect" ( $\geq 2$ cautions or $\geq 1$ delay), or "untestable" (based on a specific pattern of refusals) [19].

\section{Statistical analyses}

Data was analysed using SPSS version 23. Simple logistic regression was applied to assess the bivariate relationship through unadjusted Odds Ratios (OR) between the dependent and independent variables. The p-value was relaxed up to 0.20 in order to take all significant variables as confounding variables in the multivariate analysis [[iv]]. Hence, multivariate logistic regression was run to measure the dynamics among the potential predictors for the delayed development among children and present results in terms of Adjusted Odds Ratios (AOR) with $95 \%$ confidence intervals ( $95 \% \mathrm{Cl}$ ).

The outcome variable was the children's developmental status as a binary variable (delayed development vs. normal development). Socio-demographic characteristics, medical history and dietary practices are included as independent variables, because they can theoretically affect development delay (Figure 2).

The reporting follows the STROBE statement for cross-sectional studies (see Supplementary Appendix 1).

\section{Results}

Developmental status

Out of the total 185 children, 8 children (4.3\%) were untestable for developmental status even after rescreening. Therefore, the analysis is based on 177 children. Result of prevalence of suspected Global development delays based on developmental milestones in all domains and separated for each domain are presented in Table 1. According to this, $61.1 \%(n=108)$ showed a suspected delay at the global level. The delay was most pronounced in personal and social behaviour $(62,1 \%, n=110)$, whereas for language $70.6 \%(n=125)$ showed a normal development. 
Table 1

Prevalence of suspected global developmental delay $(n=177)$

\begin{tabular}{|cll|}
\hline & Categories & $\boldsymbol{n}(\%)$ \\
\hline Global development & Normal & $69(38.9)$ \\
Development in domains & Suspected delay & $108(61.1)$ \\
\hline Personal and social behaviour & Normal & $67(37.9)$ \\
\cline { 2 - 3 } & Delay & $81(45.8)$ \\
\hline Fine motor & Caution & $29(16.3)$ \\
\hline \multirow{2}{*}{ Language } & Normal & $113(63.8)$ \\
\hline \multirow{2}{*}{ Gross motor } & Delay & $43(24.3)$ \\
\hline & Caution & $21(11.9)$ \\
\hline & Normal & $125(70.6)$ \\
\hline & Delay & $23(13.0)$ \\
\hline & Caution & $29(16.4)$ \\
\hline & Normal & $115(65.0)$ \\
\hline & Delay & $28(15.8)$ \\
\hline & Caution & $34(19.2)$ \\
\hline
\end{tabular}

Socio-demographic characteristics and developmental status

Comparisons of socio-demographic characteristics between children having normal development and suspected developmental delay are presented in Table 2 . The comparison revealed that age $(p<0.01)$, monthly income $(p=0.04)$, mother's $(p=0.01)$ as well as father's education $(p=0.04)$, and family size were $(p=0.01)$ are significantly related with suspected developmental delay. All other socio-demographic factors did not show any significant association with developmental status. 
Table 2

Socio-demographic characteristics and developmental status $(\mathrm{n}=177)$

\begin{tabular}{|c|c|c|c|c|c|c|}
\hline $\begin{array}{l}\text { Socio-demographic } \\
\text { characteristics }\end{array}$ & Categories & $n$ & $\begin{array}{l}\begin{array}{l}\text { Normal } \\
\text { development }\end{array} \\
n(\%)\end{array}$ & $\begin{array}{l}\text { Delayed } \\
\text { development } \\
n(\%)\end{array}$ & $\begin{array}{l}O R \\
C I)\end{array}$ & $\begin{array}{l}p- \\
\text { value }\end{array}$ \\
\hline \multirow[t]{2}{*}{ Gender } & Male & 78 & $27(34.6)$ & $51(65.4)$ & $\begin{array}{l}1.39 \\
(0.75- \\
2.57)\end{array}$ & 0.29 \\
\hline & Female & 99 & $42(42.4)$ & $57(57.6)$ & Reference & \\
\hline \multirow[t]{2}{*}{$\begin{array}{l}\text { Age } \\
\text { (in months) }\end{array}$} & $6-24$ & 151 & $50(33.1)$ & $101(66.9)$ & $\begin{array}{l}5.48 \\
(2.16- \\
13.9)\end{array}$ & $\dot{0} 01$ \\
\hline & $25-59$ & 26 & $19(73.1)$ & 7 (26.9) & Reference & \\
\hline \multirow[t]{2}{*}{$\begin{array}{l}\text { Monthly income } \\
\text { (in PKR) }\end{array}$} & $<15,000$ & 121 & $41(33.9)$ & $80(66.1)$ & $\begin{array}{l}1.95 \\
(1.02- \\
3.72)\end{array}$ & 0.04 \\
\hline & $\geq 15,000$ & 56 & $28(50.0)$ & $28(50.0)$ & Reference & \\
\hline \multirow[t]{2}{*}{ Mother's education } & Illiterate & 128 & $43(33.6)$ & $85(66.4)$ & $\begin{array}{l}2.23 \\
(1.14- \\
4.36)\end{array}$ & 0.01 \\
\hline & $\geq$ Primary & 49 & $26(53.1)$ & $23(46.9)$ & Reference & \\
\hline \multirow[t]{2}{*}{ Mother's occupation } & Working & 19 & $10(52.6)$ & $9(47.4)$ & Reference & 0.20 \\
\hline & Housewife & 158 & 59 (37.3) & $99(62.7)$ & $\begin{array}{l}1.86 \\
(0.72- \\
4.85)\end{array}$ & \\
\hline \multirow[t]{2}{*}{ Father's education } & Illiterate & 109 & $36(33.0)$ & $73(67.0)$ & $\begin{array}{l}1.91 \\
(1.02- \\
3.55)\end{array}$ & 0.04 \\
\hline & $\geq$ Primary & 68 & $33(48.5)$ & $35(51.5)$ & Reference & \\
\hline \multirow[t]{2}{*}{ Family size } & $<8$ & 40 & $22(55.0)$ & $18(45.0)$ & Reference & 0.01 \\
\hline & $>8$ & 137 & $47(34.3)$ & $90(65.7)$ & $\begin{array}{l}2.34 \\
(1.14- \\
4.79)\end{array}$ & \\
\hline \multirow[t]{2}{*}{ Family structure } & Joint & 72 & $30(41.7)$ & $42(58.3)$ & Reference & 0.54 \\
\hline & Nuclear & 105 & 39 (37.1) & $66(62.9)$ & $\begin{array}{l}1.21 \\
(0.65- \\
2.32)\end{array}$ & \\
\hline
\end{tabular}


A significant association with delayed development was found for the frequency of hospital visits $(\mathrm{p}=$ 0.03), which are visits to hospital in the past six months due to diarrhoea, respiratory infections, or because of any other illness confirmed from their medical record to avoid any recall bias, history of tuberculosis (TB) contact $(p=0.01)$, which is a child with close contact to a TB smear positive adult patient at home or in the near surroundings, and breastfeeding practices $(p=0.01)$. Furthermore, history of worm infestation $(p=0.14)$ was included in the multivariate analysis as the level of significance was relaxed for this analysis $(p<0.20)$. All other variables, such as complementary feeding practices (complementary food was probed in detail from mothers according to WHO recommendations by showing them different utensils and food charts to assess quantity, variety and frequency of food), hygienic practices, vaccination, and history of measles, were not related to delayed development among children (Table 3). 
Table 3

Medical history, dietary practices and developmental status $(\mathrm{n}=177)$

\begin{tabular}{|c|c|c|c|c|c|c|}
\hline $\begin{array}{l}\text { Medical history and } \\
\text { dietary practices }\end{array}$ & Categories & $n$ & $\begin{array}{l}\text { Normal } \\
\text { Development } \\
n(\%)\end{array}$ & $\begin{array}{l}\text { Delayed } \\
\text { development } \\
n(\%)\end{array}$ & $\underset{C l)}{O R}(95 \%$ & $\begin{array}{l}p- \\
\text { value }\end{array}$ \\
\hline \multirow[t]{2}{*}{$\begin{array}{l}\text { Complementary } \\
\text { feeding practices }\end{array}$} & Poor & 136 & $18(43.9)$ & $23(56.1)$ & $\begin{array}{l}1.30 \\
(0.64- \\
2.65)\end{array}$ & 0.46 \\
\hline & Good & 41 & $51(37.5)$ & $85(62.5)$ & Reference & \\
\hline \multirow[t]{2}{*}{ Hygienic practices } & Poor & 157 & $8(40.0)$ & $12(60.0)$ & $\begin{array}{l}1.05 \\
(0.41- \\
2.71)\end{array}$ & 0.92 \\
\hline & Good & 20 & $61(38.9)$ & $96(61.1)$ & Reference & \\
\hline \multirow[t]{2}{*}{ History of TB contact } & Yes & 77 & $22(28.6)$ & $55(71.4)$ & $\begin{array}{l}2.22 \\
(1.18- \\
4.17)\end{array}$ & 0.01 \\
\hline & No & 100 & $47(47.0)$ & $53(53.0)$ & Reference & \\
\hline \multirow[t]{2}{*}{$\begin{array}{l}\text { History of worm } \\
\text { infestation }\end{array}$} & Yes & 41 & $12(29.3)$ & $29(70.7)$ & $\begin{array}{l}1.74 \\
(0.82- \\
3.71)\end{array}$ & 0.14 \\
\hline & No & 136 & $57(41.9)$ & $79(58.1)$ & Reference & \\
\hline \multirow[t]{2}{*}{ History of measles } & Yes & 26 & $9(34.6)$ & $17(65.4)$ & $\begin{array}{l}1.24 \\
(0.52- \\
2.98)\end{array}$ & 0.62 \\
\hline & No & 151 & $60(39.7)$ & $91(60.3)$ & Reference & \\
\hline \multirow{2}{*}{$\begin{array}{l}\text { Frequency of hospital } \\
\text { visits }\end{array}$} & $1-7$ & 95 & $44(46.3)$ & $51(53.7)$ & Reference & 0.03 \\
\hline & $8-15$ & 82 & $25(30.5)$ & $57(69.5)$ & $\begin{array}{l}1.96 \\
(1.05- \\
3.65)\end{array}$ & \\
\hline \multirow[t]{2}{*}{ Breastfeeding } & Mixed & 143 & 49 (34.3) & $94(65.7)$ & $\begin{array}{l}2.74 \\
(1.27- \\
5.89)\end{array}$ & 0.01 \\
\hline & Exclusive & 34 & $20(58.8)$ & $14(41.2)$ & Reference & \\
\hline \multirow[t]{2}{*}{ Vaccination } & Incomplete & 45 & $14(31.1)$ & $31(68.9)$ & $\begin{array}{l}1.58 \\
(0.77- \\
3.24)\end{array}$ & 0.21 \\
\hline & Complete & 132 & $55(41.7)$ & 77 (58.3) & Reference & \\
\hline
\end{tabular}




\begin{tabular}{|c|c|c|c|c|c|c|}
\hline $\begin{array}{l}\text { Medical history and } \\
\text { dietary practices }\end{array}$ & Categories & $n$ & $\begin{array}{l}\text { Normal } \\
\text { Development } \\
n(\%)\end{array}$ & $\begin{array}{l}\text { Delayed } \\
\text { development } \\
n(\%)\end{array}$ & $\begin{array}{l}O R \\
C I)\end{array}$ & $\begin{array}{l}p- \\
\text { value }\end{array}$ \\
\hline \multirow[t]{2}{*}{ History of pica } & Yes & 58 & $22(37.9)$ & $36(62.1)$ & $\begin{array}{l}1.06 \\
(0.56- \\
2.03)\end{array}$ & 0.84 \\
\hline & No & 119 & $47(39.5)$ & $72(60.5)$ & Reference & \\
\hline \multirow[t]{2}{*}{ History of anemia } & Yes & 76 & $31(40.8)$ & $45(59.2)$ & $\begin{array}{l}0.87(0.7- \\
1.61)\end{array}$ & 0.66 \\
\hline & No & 101 & 38 (37.6) & $63(62.4)$ & Reference & \\
\hline
\end{tabular}

\section{Multivariate logistic regression}

All variables which were found significant $(\mathrm{p} \leq 0.20)$ in the simple logistic regression models (Tables 2 and 3) were included in the multivariate logistic regression analysis. As multicollinearity was found between mother's education and father's education, we only kept mother's education in the analysis to account for the fact that mother's education was found to be a significant predictor of child development in previous studies [].

In the multivariate logistic regression model, only a younger age (6-24 months vs. 25-59 months) of the child (AOR $=4.53,95 \% \mathrm{Cl}: 1.56-13.10, p<0.01)$, history of TB contact $(A O R=2.67,95 \% \mathrm{Cl}: 1.30-5.49, p<$ $0.01)$, and mixed breastfeeding practices $(A O R=3.07,95 \% \mathrm{Cl}: 1.24-7.56, p=0.01)$ remained significantly associated with developmental delays (Table 4). 
Table 4

Multivariate logistic regression for predictors of developmental delay $(n=$ 177)

\begin{tabular}{|c|c|c|c|}
\hline Independent variables & Categories & AOR (95\% Cl) & $p$-value \\
\hline \multirow[t]{2}{*}{ Age (in months) } & $6-24$ & $4.53(1.56-13.10)$ & \multirow[t]{2}{*}{$<0.01$} \\
\hline & $25-59$ & Reference & \\
\hline \multirow[t]{2}{*}{ Monthly income (in PKR) } & $<15,000$ & $1.43(0.64-3.17)$ & \multirow[t]{2}{*}{0.37} \\
\hline & $\geq 15,000$ & Reference & \\
\hline \multirow[t]{2}{*}{ Mother's education } & Illiterate & $1.65(0.75-3.62)$ & \multirow[t]{2}{*}{0.21} \\
\hline & $\geq$ Primary & Reference & \\
\hline \multirow[t]{2}{*}{ Mother's occupation } & Working & Reference & \multirow[t]{2}{*}{0.22} \\
\hline & Housewife & $0.50(0.16-1.52)$ & \\
\hline \multirow[t]{2}{*}{ Family size } & $<8$ & Reference & \multirow[t]{2}{*}{0.14} \\
\hline & $>8$ & $1.87(0.80-4.40)$ & \\
\hline \multirow[t]{2}{*}{ History of TB contact } & Yes & $2.67(1.30-5.49)$ & \multirow[t]{2}{*}{$<0.01$} \\
\hline & No & Reference & \\
\hline \multirow[t]{2}{*}{ History of worm infestation } & Yes & $2.02(0.85-4.81)$ & \multirow[t]{2}{*}{0.11} \\
\hline & No & Reference & \\
\hline \multirow[t]{2}{*}{ Frequency of hospital visits } & $1-7$ & Reference & \multirow[t]{2}{*}{0.10} \\
\hline & $8-15$ & $1.87(0.88-3.97)$ & \\
\hline \multirow[t]{2}{*}{ Breastfeeding } & Mixed & $3.07(1.24-7.56)$ & \multirow[t]{2}{*}{0.01} \\
\hline & Exclusive & Reference & \\
\hline
\end{tabular}

\section{Discussion}

The study revealed a very high prevalence of suspected developmental delays (61.1\%) within severe acute malnourished children under-five. Malnutrition in children is one of the main reasons for developmental delay which is having a lifelong adverse impact on health $\left[{ }^{10},{ }^{22}\right.$, ]. Undernutrition affects the child's behaviour and temperament. It is one of the reasons for low economic productivity in adulthood $\left[{ }^{22},,\right]$. Because of being lethargic and apathetic, malnourished children have problems in understanding information and they are least interested in their surroundings. This results in delayed social interaction skills. Personal and social development in the initial years of life is the main factor responsible for desirable mental health and performance in adulthood. Therefore, the recognition of personal, social and behavioural problems in young children is very important [. Within this study, we 
found that in the domain of personal and social behaviour, almost half of the children (45.8\%) have delayed developments, with an additional $16.3 \%$ being in the caution zone. This result is enforced by previously described theories and can, therefore, be generalized to other study settings $\left[{ }^{24}, 25\right]$.

Children in our study were also found to be affected in language and motor adaptive skills. Previous research explained that due to malnutrition children are suffering from multiple micronutrient deficiencies (like calcium and vitamin D), which are important for skeletal muscle function. For that reason, a deficiency of these micronutrients affects motor skills [ $\left.{ }^{6}\right]$. Nutritional insufficiencies even in acute stage may damage the cognitive profile and entire auditory system in children resulting in verbal and written language problems. It has already been proved that height, weight and head circumferences are directly related to high incidence of delays in motor skills and the language domain [ ].

Child development proceeds through a gradual multifaceted interaction, probably by the parents or caregiver's education level, living and working conditions, social circumstances, availability of health facilities, and the physical environment. An unconstructive social or external environment in early life years is mostly linked to compromised development. Every region or community has their own circumstances. For that reason, locally targeted research and interventions are needed to go forward $\left.{ }^{26}\right]$. In the present study, mother's education, monthly income of a family, frequent hospital visits due to repeated illness, and family size were significantly linked to developmental delays in the bivariate analysis. This has also been shown in previous studies $[1,3,10,26]$. Comparable research in the Indonesian slum area and in the United States revealed that low maternal education and low family income, is strongly associated with delayed development in young children $\left[{ }^{1},,\right]$. This is due to the fact that maternal education has a direct effect on proper medical follow-up in the antenatal period, effective family planning, optimal nutrition and child health care $\left.{ }^{[22}\right]$.

In our study, exclusive breastfeeding was significantly associated with normal child development. In addition, a strong correlation between breastfeeding and progressive developmental outcomes in children was proven previously. This can be explained by the nutritive value of breast milk and the strong emotional bonding between mother and child. Studies also relate breastfeeding with high score achievements in cognitive tests and in motor and mental development [ ]. A cluster-randomized trial did intervene for breastfeeding promotion and found significant results for children long-term outcomes in health and neuro-development $\square$.

The risk of developmental delay was found to be increased in the first two years of age. It was also observed previously, that if an infant is suffering from malnutrition in early childhood the risk of developmental delay is enhanced. Furthermore, this is an indication of serious physical or psycho-social problems. Development in infancy and toddler period is fast and easily influenced by environmental and social-demographic variables $[1,30,32]$.

In contrary to other studies, the history of a child's close contact with a TB smear positive adult patient at home or in near surroundings is significant in the present study. For understanding this phenomenon, 
more in-depth research is required. One explanation might be that these children could have had an undiagnosed latent or active TB because of malnutrition, low immune status $\left[2,{ }^{10}\right]$, or the contact with smear positive TB patients. Therefore, a complete physical examination along with laboratory investigations is required for the diagnosis of TB in these children.

Strengths and limitations

Besides the missing information on TB status of the children within this study, another major limitation is the cross-sectional design. Monitoring the child's developmental and nutritional status over a longer time period would impart a better perceptiveness because of the dynamic nature of growth and development. The strength of our study is that we have used the Denver Developmental Screening Test II, which is a validated scale for developmental assessment of children. Furthermore, this assessment has been conducted by well-trained medical staff using established protocols. Moreover, to our knowledge, this is the first study in rural areas of Punjab, Pakistan, to investigate the loss of developmental potential in children with severe acute malnutrition.

\section{Conclusion}

Severe acute malnourished children have a high prevalence of suspected global developmental delay. Developmental delay and malnutrition are two major interrelated public health problems, hindering the achievement of SDGs in children of low-resource countries. Thus, timely identification and proper management of developmental delays in children should be reinforced to meet enduring growth and developmental needs. The results of this study will be helpful for policy makers to develop strategies for prevention and treatment of growth failure and developmental delay in these vulnerable malnourished children.

\section{Abbreviations}

AOR

Adjusted odds ratios

$\mathrm{Cl}$

Confidence interval

DDST II

Denver Development Screening Tool II

MUAC

Mid-upper arm circumference

OR

Odds ratio

OTP

Outpatient therapeutic programs

PKR 
Pakistani Rupees

RUTF

Ready-to-use therapeutic food

SAM

Severe acute malnutrition

SC

Stabilization centre

SDG

Sustainable Development Goal

SPSS

Statistical Package for Social Sciences

TB

Tuberculosis

WHO

World Health Organization

WHZ

Weight-for-height z-score

\section{Declarations}

\section{Ethical Approval and Consent to Participate}

Ethical approval was given by the Ethical Review and Advanced Study Research Board of the University of Punjab, Pakistan (ref no; “9/2352-ACAD”) and the District Health Office of the DG Khan. Parents were informed about the study objectives in their local language at the health centres by the study team. Written informed consent of parents, verified by signature or thumb impression, was recorded.

\section{Consent for Publication}

Not applicable.

\section{Availability of Data and Materials}

Data is available from corresponding author upon reasonable request.

\section{Competing interests}

The authors declare that they have no competing interests

\section{Funding}

This research received no supporting funds from any funding agency in the public, commercial, or not-forprofit sector. 


\section{Authors contributions}

JS, RZ, and GMJB conceptualized the idea and conducted study. JS analysed the study. JS and AF drafted the manuscript. RZ and FF revised it critically for important for intellectual content. All authors have approved the final version.

\section{Acknowledgements}

We thank the families who took part in this study. We are also grateful to Ms. Mudasir Mustafa (Utah State University, USA) for helping us in the analysis. We are thankful to the staff at the Integrated Reproductive Maternal Newborn Child Health \& Nutrition Program (IRMNCH), Dera Ghazi Khan, Pakistan for their support conducting the study.

We acknowledge support from the German Research Foundation (DFG) and the Open Access Publication Fund of Charité - Universitätsmedizin Berlin.

\section{References}

1. Zhang J, Guo S, Li Y, Wei Q, Zhang C, Wang X, Luo S, Zhao C, Scherpbier RW. Factors influencing developmental delay among young children in poor rural China: a latent variable approach. BMJ Open. 2018;8(8):e021628.

2. Gupta N, Kabra M. Approach to the diagnosis of developmental delay - the changing scenario. Indian Journal Medical Research. 2014;139:4-6.

3. Grantham-McGregor S, Cheung YB, Cueto S, Glewwe P, Richter L, Strupp B, International Child Development Steering Group. Developmental potential in the first 5 years for children in developing countries. Lancet. 2007;369(9555):60-70.

4. World Health Organization. WHO child growth standards and the identification of severe acute malnutrition in infants and children: joint statement by the World Health Organization and the United Nations Children's Fund. Geneva: World Health Organization; 2009.

5. World Health Organization. Guideline: Updates on the management of severe acute malnutrition in infants and children. Geneva: World Health Organisation; 2013.

6. Saleem J, Zakar R, Zakar MZ, Belay M, Rowe M, Timms PM, Scragg R, Martineau AR. High-dose vitamin D3 in the treatment of severe acute malnutrition: a multicenter double-blind randomized controlled trial. Am J Clin Nutr. 2018;107(5):725-33.

7. Lelijveld N, Seal A, Wells JC, Kirkby J, Opondo C, Chimwezi E, Bunn J, Bandsman R, Heyderman RS, Nyirenda MJ, Kerac M. Chronic disease outcomes after severe acute malnutrition in Malawian children (ChroSAM): a cohort study. Lancet Glob Health. 2016;4(9): e654-62.

8. Galler JR, Bryce C, Eaglesfield D. Socioeconomic outcomes in adults malnourished in the first year of life: a 40-year study. Pediatrics. 2012;130(1):e1-7. 
9. National Research Council, Institute of Medicine Committee on Integrating the Science of Early Childhood Development. From neurons to neighbourhoods: The science of early childhood development. Washington, DC: National Academies Press; 2000.

10. Chattopadhyay N, Saumitra M. Developmental Outcome in Children with Malnutrition. Journal of Nepal Paediatric Society. 2016;36(2):170-7.

11. Lo S, Das P, Horton R. A good start will ensure sustainable future for all. Lancet. 2017;389(10064):89.

12. Bogale A, Stoecker BJ, Kennedy T, Hubbs-Tait L, Thomas D, Abebe Y, Hambidge KM. Nutritional status and cognitive performance of mother-child pairs in Sidama, Southern Ethiopia. Matern Child Nutr. 2013;9(2):274-84.

13. Engle PL, Black MM, Behrman JR, De Mello MC, Gertler PJ, Kapiriri L, Martorell R, Young ME. Strategies to avoid the loss of developmental potential in more than 200 million children in the developing world. Lancet. 2007;369(9557):229-42.

14. Grove J, Claeson M, Bryce J, Amouzou A, Boerma T, Waiswa P, Victora C. Maternal, newborn, and child health and the Sustainable Development Goals - a call for sustained and improved measurement. Lancet. 2015;386(10003):1511-4.

15. UNICEF. National Nutritional Survey 2018, Pakistan. New York: UNICEF; 2019.

16. MEASURE DHS. Demographic and Health surveys. Calverton: MEASURE DHS; 2013.

17. De Onis M, Onyango AW, Van den Broeck J, Chumlea WC, Martorell R. Measurement and standardization protocols for anthropometry used in the construction of a new international growth reference. Food Nutr Bull. 2004;25(Suppl. 1):S27-36.

18. Frankenburg WK, Dodds J, Archer P, Shapiro H, Bresnick B. The Denver II: A Major Revision and Restandardization of the Denver Developmental Screening Test. Pediatrics. 1992;89(1):91-7.

19. Bursac Z, Gauss CH, Williams DK, Hosmer DW. Purposeful selection of variables in logistic regression. Source Code Biol Med. 2008;3:17.

20. Thomas D, Strauss J, Henriques M. How does mother's education affect child height? Journal of Human Resources. 2016;26(2):183-211.

21. Liu J, Raine A. The effect of childhood malnutrition on externalizing behaviour. Curr Opin Pediatr. 2006;18(5):565-70.

22. Galler JR, Bryce C, Waber DP. Socioeconomic outcomes in adults malnourished in the first year of life: a 40-year study. Pediatr. 2012;130:e1-7

23. Hamadani JD, Fuchs GJ, Osendarp SJ, Khatun F, Huda SN, Grantham-McGregor SM. Randomized controlled trial of the effect of zinc supplementation on the mental development of Bangladeshi infants. Am J Clin Nutr. 2001;74(3):381-6.

24. World Health Organization. Developmental difficulties in early childhood: prevention, early identification, assessment and intervention in low-and middle-income countries: a review. Geneva: World Health Organization; 2012. 
25. Jimoh AO, Anyiam JO, Yakubu AM. Relationship between child development and nutritional status of under-five Nigerian children. South African J Clin Nutr. 2018;31:50-4.

26. Hill EL. Non-specific nature of specific language impairment: a review of the literature with regard to concomitant motor impairments. Int J Lang Commun Disord. 2001;36(2):149-71.

27. Gunardi H, Nugraheni RP, Yulman AR, Soedjatmiko S, Sekartini R, Medise BE, Wirahmadi A, Melina E. Growth and developmental delay risk factors among under-five children in an inner-city slum area. Pediatrics Indonesian. 2019;59(5):276-83.

28. Hurt H, Betancourt LM. Turning One Year of Age in a Low Socioeconomic Environment: A Portrait of Disadvantage. J Dev Behav Pediatr. 2017;38(7):493-500.

29. Rao MR, Hediger ML, Levine RJ, Naficy AB, Vik T. Effect of breastfeeding on cognitive development of infants born small for gestational age. Acta Paediatr. 2002;91(3):267-74.

30. Yakoob MY, Lo CW. Nutrition (micronutrients) in child growth and development: a systematic review on current evidence, recommendations and opportunities for further research. J Dev Behav Pediatr. 2017;38(8):665-79.

31. Kramer MS, Aboud F, Mironova E, Vanilovich I, Platt RW, Matush L, Igumnov S, et al. Breastfeeding and child cognitive development: new evidence from a large randomized trial. Arch Gen Psychiatry. 2008;65(5):578-84.

\section{Figures}




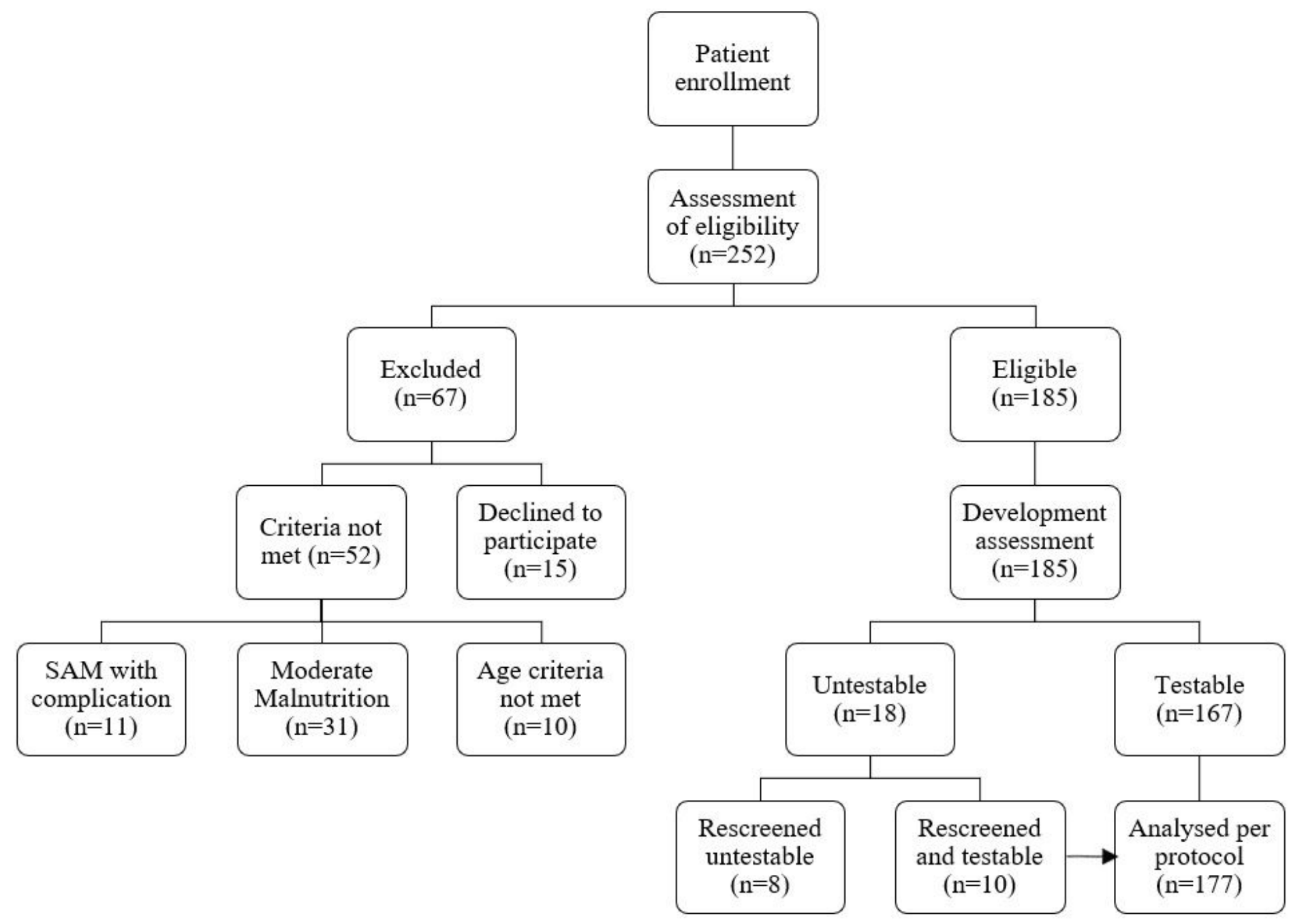

\section{Figure 1}

Flowchart of sample selection and developmental screening

Medical history and dietary practices

- Complimentary feeding practices

- Hygienic practices

- History of TB contact

- History of worm infestation

- History of measles

- Frequency of hospital visits

- Breastfeeding

- Vaccination

- History of pica

- History of anemia

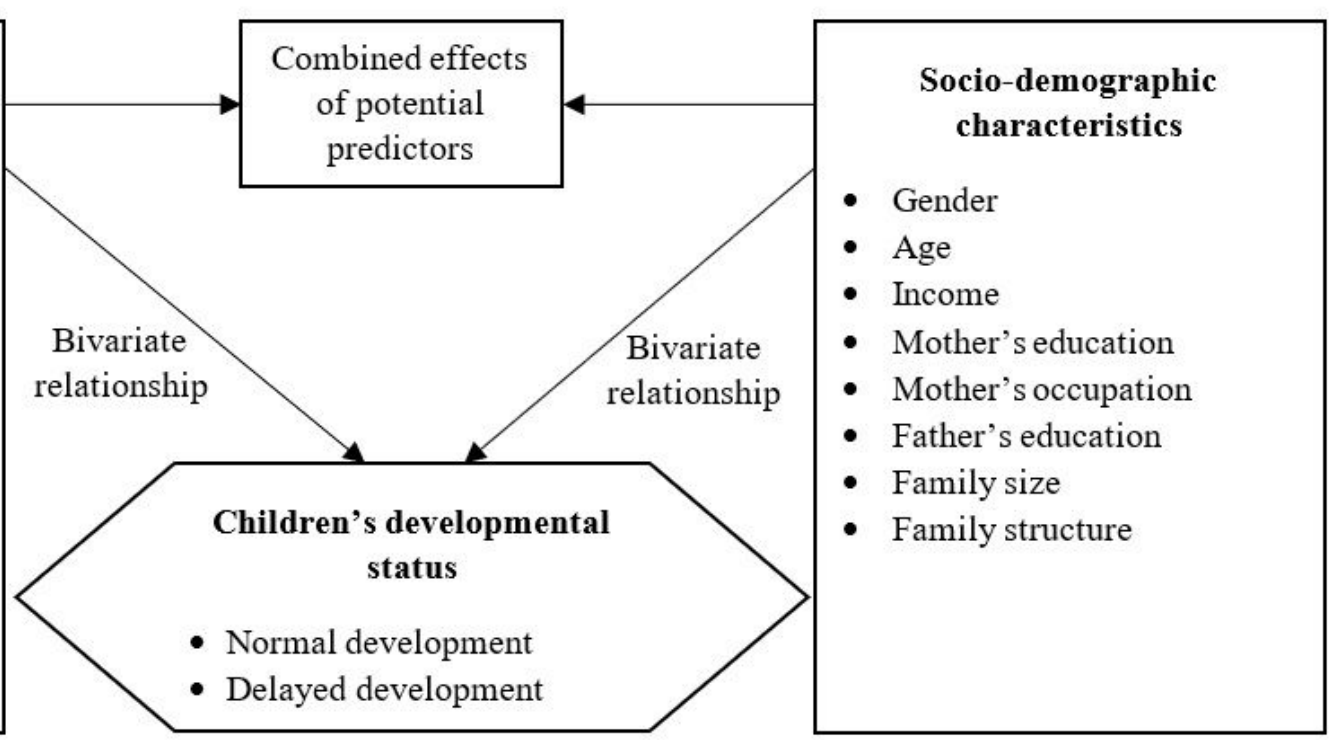


Relationships between variables affecting developmental delay

\section{Supplementary Files}

This is a list of supplementary files associated with this preprint. Click to download.

- SupplementaryAppendix1STROBEchecklistcrosssectional.docx 